\title{
Successful treatment of atrial tachycardias with flecainide acetate
}

\author{
J E CREAMER, A W NATHAN, A J CAMM \\ From the Department of Cardiology, St Bartholomew's Hospital, London
}

SUMMARY Intravenous flecainide successfully terminated atrial tachycardia in three patients. Maintenance treatment with oral flecainide prevented the recurrence of tachycardia for up to three years. These results suggest an additional use for flecainide which should be further explored.

Flecainide acetate is a new synthetic antiarrhythmic drug which is classified as a Vaughan Williams class IC agent. ${ }^{2}$ It has been shown to be effective in the treatment of junctional arrhythmias ${ }^{3}$ and in certain ventricular arrhythmias, ${ }^{4-6}$ but there are few published data on its use in atrial arrhythmias. It seems effective in the conversion of atrial fibrillation to sinus rhythm, but is much less effective for terminating atrial flutter. ${ }^{7}$ We report three patients with atrial tachycardias who were successfully treated by intravenous flecainide and in whom sinus rhythm was maintained with the oral preparation.

\section{Patients and methods}

CASE 1

A 23 year old man with the Wolff-Parkinson-White syndrome (type A) underwent successful cryoablation of a left lateral accessory pathway and incidental closure of a persistent foramen ovale. Nine days postoperatively he developed frequent atrial extrasystoles and episodes of atrial tachycardia and fibrillation, with intermittent left bundle branch block. There was no evidence of pre-excitation, and intracardiac electrophysiological studies confirmed the atrial origin of the arrhythmia. Tachycardia became incessant and was not terminated by disopyramide $150 \mathrm{mg}$ given intravenously. Verapamil $5 \mathrm{mg}$ intravenously produced only temporary suppression. On the twelfth postoperative day flecainide $75 \mathrm{mg}$ was given intravenously and completely suppressed tachycardia and the associated atrial ectopic activity. With maintenance treatment with oral flecainide $150 \mathrm{mg}$

Requests for reprints to Dr J E Creamer, Department of Cardiology, St Bartholomew's Hospital, West Smithfield, London EC1A 7BE.

Accepted for publication 18 September 1984 twice daily he has remained asymptomatic for three months and his electrocardiogram shows uninterrupted sinus rhythm.

\section{CASE 2}

A 57 year old man with an eight year history of recurrent attacks of palpitation and syncope was diagnosed by electrophysiological study as having chaotic atrial tachycardia. Thyroid function tests were normal. Treatment, over a five year period, with digoxin, verapamil, metoprolol, disopyramide, atenolol, sotalol, and propranolol, alone and in combinations of two drugs, proved ineffective at suppressing the attacks. He was readmitted with an episode of tachycardia which had started four days previously. On admission his heart rate was approximately 200 beats/min and blood pressure $95 / 70 \mathrm{~mm} \mathrm{Hg}$. Flecainide, $90 \mathrm{mg}$ intravenously, terminated the tachycardia, but it recurred 30 minutes later at the slower atrial rate of 150 beats/min. A further $75 \mathrm{mg}$ of flecainide was given, which gradually slowed the tachycardia until sinus rhythm emerged. He remained free of symptoms and was in sinus rhythm six months later, taking oral flecainide $150 \mathrm{mg}$ twice daily.

\section{CASE 3}

A 33 year old man was admitted with a two year history of palpitation, which lasted from one hour to several days and was occasionally associated with syncope. The attacks had increased in frequency, occurring on alternate days. Prophylaxis with propranolol and disopyramide, either alone or in combination, was ineffective. Resting electrocardiograms showed a narrow $Q R S$ complex tachycardia at a rate of $160-170$ beats/min and left ventricular hypertrophy on voltage criteria. Thyroid function tests were normal. A first pass nuclear angiogram showed globally impaired left ventricular function, and at cardiac 


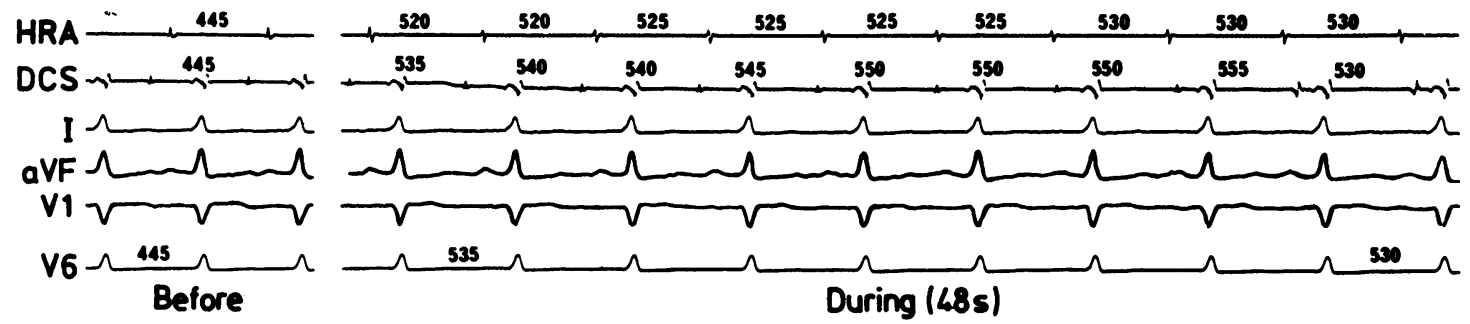

Figure Electrocardiograms and electrograms showing the effect of intravenous flecainide on automatic left atrial tachycardia (case 3). Beforeflecainide administration the left atrial focus has a discharge frequency of 135 beats/min (445 ms). During infusion there is gradual slowing of the tachycardia rate with the emergence of sinus rhythm at a rate of 113 beats/min (530 ms) after $48 \mathrm{~s}$. Note the change in atrial activation sequence from earliest activity in the distal coronary sinus electrogram (DCS) before flecainide administration to earliest activity in the high right atrium (HRA) during flecainide infusion.

catheterisation left ventriculography showed a large cavity with general hypokinesis and ejection fraction reduced at $25 \%$. Intracardiac pressures were normal, as was coronary arteriography.

Electrophysiological study showed an automatic left atrial tachycardia. Intravenous flecainide $120 \mathrm{mg}$ slowed the tachycardia from 135 beats/min, and sinus rhythm resulted after $48 \mathrm{~s}$ at a rate of 113 beats/min (Figure).

With maintenance treatment with flecainide $100 \mathrm{mg}$ three times daily he has remained symptom free for three years. Excercise electrocardiograms and 24 hour Holter monitoring have shown normal sinus rhythm.

\section{Discussion}

Initial studies of flecainide showed it to be effective against atrial and ventricular arrhythmias induced in experimental animals by either chemical or ischaemic methods. ${ }^{89}$

The electrophysiological effects of flecainide have been studied extensively, and in general its effect on conduction is more profound than on refractoriness. In particular, it causes a consistent increase in the PA interval, a measure of the intra-atrial conduction time, by a mean of $22 \% .{ }^{10}$ Increases in atrial refractoriness have been shown, ${ }^{10}$ but these are usually small and fail to reach statistical significance, although Pop et al found a significant increase of $17 \cdot 5 \% .{ }^{11}$ In the same report flecainide successfully prevented the induction of atrial tachyarrhythmias by programmed stimulation in nine out of 16 patients studied.

Orning reported a single case of chronic atrial tachycardia where temporary suppression of the arrhythmia was achieved by intravenous flecainide. ${ }^{12}$ Somani reported the effective suppression of atrial extrasystoles in two out of three patients given flecainide intravenously but found no effect on chronic atrial fibrillation in another two patients. ${ }^{13}$ Nathan et al treated 10 patients with paroxysmal atrial fibrillation with intravenous flecainide and produced conversion to sinus rhythm in nine. ${ }^{7}$ By contrast, in the same report, termination of paroxysmal atrial flutter by intravenous flecainide was achieved in only two out of a further 10 patients, although the atrial rate slowed in all cases and slowing of the ventricular response occurred in nine.

It is of interest that in two cases in the present report tachycardia reversion occurred by progressive slowing until sinus rhythm emerged and resumed control. This is in contrast to the effect of flecainide on junctional re-entrant tachycardias where termination is sudden and where there is a more pronounced effect on the refractoriness of some of the individual tissue components of the junctional re-entrant circuit. ${ }^{310}$ In case 1 flecainide successfully abolished the repetitive atrial ectopic activity, which suggests that it may also selectively suppress the enhanced automaticity of ectopic foci.

The efficacy of flecainide against atrial tachycardias shown by these cases suggests a potential additional use for the drug, although comparative studies are required to define its precise role.

AWN and AJC are supported by the British Heart Foundation.

\section{References}

1 Cowan JC, Vaughan Williams EM. Characterisation of a new oral antiarrhythmic drug, flecainide (R-818). Eur $\mathcal{F}$ Pharmacol 1981; 73: 333-42.

2 Campbell TJ. Kinetics of onset of rate-dependent effects of class I antiarrhythmic drugs are important in determining their effects on refractoriness in guinea-pig ventricle, and provide a theoretical basis for their subclassification. Cardiovasc Res 1983; 17: 344-52.

3 Hellestrand KJ, Nathan AW, Bexton RS, et al. Cardiac electrophysiologic effects of flecainide acetate for paroxysmal reentrant junctional tachycardias. Am $\mathcal{F}$ Cardiol 1983; 51: 770-6.

4 Anderson JL, Stewart JR, Perry BA, et al. Oral 
flecainide acetate for the treatment of ventricular arrhythmias. $N$ Engl $\mathcal{F}$ Med 1981; 305: 473-7.

5 Hodges M, Haugland JM, Granrud G, et al. Suppression of ventricular ectopic depolarizations by flecainide acetate, a new antiarrhythmic agent. Circulation 1982; 65. 879-85.

6 The Flecainide-Quinidine Research Group. Flecainide versus quinidine for treatment of chronic ventricular arrhythmias: a multicenter clinical trial. Circulation 1983; 67: 1117-23.

7 Nathan AW, Hellestrand KJ, Bexton RS, Camm AJ. Clinical use of intravenous flecainide for acute atrial, junctional and ventricular tachycardias [Abstract]. $\mathcal{F} \mathrm{Am}$ Coll Cardiol 1984; 3: 557.

8 Schmid JR, Seebeck BD, Henrie CL, Banitt EH, Kvam DC. Some antiarrhythmic actions of a new compound, R-818, in dogs and mice [Abstract]. Fed Proc 1975; 34:
775.

9 Verdouw PD, Deckers JW, Conrad GJ. Antiarrhythmic and hemodynamic actions of flecainide acetate $(R-818)$ in the ischaemic porcine heart. $f$ Cardiovasc Pharmacol 1979; 1: 473-86.

10 Hellestrand KJ, Bexton RS, Nathan AW, Spurrell RAJ, Camm AJ. Acute electrophysiological effects of flecainide acetate on cardiac conduction and refractoriness in man. Br Heart f 1982; 48: 140-8.

11 Pop T, Treese N, Kang JC, Meinertz T, Kasper W. Effect of intravenous flecainide on atrial vulnerability in man. Klin Wochenschr 1983; 61: 609-15.

12 Orning OM. Electrophysiologic effects of flecainide acetate in arrhythmias [Abstract]. In: Proceedings of the VIII World Congress of Cardiology, Tokyo, 1978; 480.

13 Somani P. Antiarrhythmic effects of flecainide. Clin Pharmacol Ther 1980; 27: 464-70. 